\title{
CORRELAÇÃO E VARIABILIDADE DA PRECIPITAÇÃO E A VAZÃO NA BACIA HIDROGRÁFICA DO RIO PIQUIRI - PR
}

CORRELATION AND VARIABILITY OF RAINFALL AND STREAMFLOW IN THE PIQUIRI-PR WATERSHED

\author{
Márcio Greyck Guimarães Correa', Emerson Galvani¹ \\ ${ }^{1}$ Universidade de São Paulo (USP), São Paulo, SP, Brasil
}

\author{
Correspondência para: Márcio Greyck Guimarães Correa (mgreyckcorrea@gmail.com) \\ doi: 10.12957/geouerj.2019.40945 \\ Recebido em: 15 ago. 2018 | Aceito em: 24 out. 2018
}

\section{RESUMO}

Esta pesquisa apresenta um estudo da análise da correlação e variabilidade entre a precipitação pluviométrica e a vazão fluvial na bacia hidrográfica do rio Piquiri-PR. Explicar a dinâmica entre essas variáveis hidrológicas auxiliam no entendimento e prevenção de alagamentos, baixa produtividade agrícola, transtornos de mobilidade urbana devido alagamento, processos erosivos, entre outros. Para o desenvolvimento desta pesquisa utilizou-se de dados do Instituto das Águas do Paraná e da Agência Nacional de Águas (ANA). Determinou-se as áreas de drenagem com a abrangência de cada posto fluviométrico e os respectivos pluviômetros, de acordo com a área de captação e realizou-se por meio de gráficos boxplots e correlações estatísticas a análise da variabilidade da precipitação e da vazão. O mês de agosto apresenta a menor precipitação média mensal, 81,2 mm, enquanto outubro apresenta a maior, 192,1 mm, a vazão média mensal da bacia hidrográfica do rio Piquiri é de 508,4 m3/s. O mês maio apresenta a maior variabilidade da precipitação e outubro é o mês com maior variabilidade para a vazão, enquanto o mês de março apresentou a menor variabilidade da precipitação e da vazão. As funções de autocorrelação indicam que para a precipitação e a vazão sem defasagem tem-se maior confiabilidade, indicando uma defasagem inferior a um mês, na escala de semanas ou dias.

Palavras-chave: bacia hidrográfica. Precipitação. vazão. boxplot. autocorrelação

\section{ABSTRACT}

This study aims a correlation and variability analysis between rainfall and streamflow in the Piquiri-PR watershed. Explain the dynamic among hydrological variables and flood prevention, helps to understand and prevent low agricultural productivity, urban mobility disorders due to flooding, erosion processes, and others. For the development of this research, we used data from Instituto das Águas do Paraná and Agência Nacional de Águas (ANA). The drainage areas were determined by the scope of each fluviometric station and the respective rain gauges, it was realyzed by means of boxplots graphics and statistical correlations the variability analysis of rainfall and streamflow. August presentes the lowest rainfall monthly average, 81,2 mm, while October presents the highest, 192,1 mm. The streamflow monthly average in the Piquiri watershed is 508,4 m3/s. May presentes the highest rainfall variability and October is the month with highest streamflow variability, while March showed the lowest rainfall and streamflow variability. The autocorrelation functions indicate that the action and absence of lag are greater, the correction of a one month low, the scale of weeks or days.

Keywords: watershed. rainfall. streamflow. boxplots. autocorrelation.

\section{INTRODUÇÃO}

A precipitação, de acordo com Bertoni e Tucci (2001), é entendida como toda água que atinge a superfície terrestre, proveniente da atmosfera. A variabilidade espaço-temporal da precipitação 
pluviométrica é resultante da dinâmica climática de uma determinada área, e interfere diretamente na dinâmica hídrica de bacias hidrográficas.

De acordo com Shelton (2009) a vazão é o escoamento da água em um canal natural, como resultante da precipitação que cai em uma área a montante do ponto de referência. Portanto, a vazão fluvial é resultante de toda a água captada pela bacia hidrográfica proveniente da precipitação pluviométrica. Para o autor, a vazão é considerada uma fonte de informação valiosa para entender como ocorre a interação entre o sistema climático e o sistema hidrológico. Explica que a precipitação produz um aumento na vazão média dos rios, enquanto que períodos de seca e diminuição da precipitação resultam em uma diminuição da vazão fluvial.

A precipitação pluviométrica é um elemento de destaque nos estudos hidroclimatológicos pois representa o input de energia e matéria na bacia hidrográfica.

A região sul do Brasil apresenta singularidades climáticas que a diferencia do restante do país, isso porque apresenta características climáticas subtropicais, marcadas pela sazonalidade térmica entre 0 verão e o inverno e pela distribuição relativamente regular da precipitação ao longo do ano, com diminuição nos meses invernais, conforme já identificado por Köppen (1948).

A análise da distribuição e variabilidade temporal e espacial da precipitação pluviométrica em bacias hidrográficas é ideal para a compreensão da dinâmica pluvial de uma região. No estado do Paraná vários estudos já abordaram a variabilidade da precipitação em bacias hidrográficas, com destaque para os estudos de Baldo (2006) que considera a bacia hidrográfica do rio Ivaí, de Zandonadi (2013) na bacia hidrográfica do rio Paraná, de Azevedo (2006) na bacia hidrográfica do rio Iguaçu, de Terassi (2015) nas bacias hidrográficas do rio Pirapó, Paranapanema III e IV, e, de Correa (2013) para a bacia hidrográfica do rio Piquiri.

Estudos de correlação entre a precipitação pluviométrica e a vazão fluvial em bacias hidrográficas vêm sendo discutido no âmbito acadêmico com exaustão por serem um importante indicador da 
vulnerabilidade da sociedade frente às intempéries climáticas. Explicar a dinâmica entre essas variáveis hidrológicas auxiliam no entendimento e prevenção de alagamentos, baixa produtividade agrícola, transtornos de mobilidade urbana devido alagamento, processos erosivos, entre outros.

A variabilidade da vazão também é um importante indicador dos riscos de inundação das planícies fluviais. Segundo Tucci (2001, p.621) "quando a precipitação é intensa a quantidade de água que chega simultaneamente ao rio pode ser superior à sua capacidade de drenagem" o que resulta na inundação das áreas ribeirinhas. Os problemas gerados pelas inundações são os mais diversos, e a gravidade depende do nível de ocupação da área e a frequência com que ocorrem as inundações.

Hewlett e Hibbert (1966) estudaram os processos hidrológicos de vazão em pequenas bacias hidrográficas nos Estados Unidos relacionando-os à precipitação. Yoshimoto e Suetsugi (1990) ressaltaram a importância dos processos de urbanização e alterações na descarga de bacias hidrográficas em áreas urbanas do Japão.

Zandonadi (2013) investigou a atuação dos sistemas atmosféricos produtores da precipitação pluviométrica sobre a bacia hidrográfica do rio Paraná, utilizando a vazão fluvial como uma variável resposta. O autor concluiu que na escala anual, as variações da precipitação resultaram em variações na vazão das usinas consideradas no estudo.

Este trabalho tem por objetivo analisar a variabilidade e correlação entre a precipitação pluviométrica e a vazão fluvial da bacia hidrográfica do rio Piquiri na escala mensal, considerando como período de análise 1976 a 2010.

\section{Procedimentos Metodológicos}

A bacia hidrográfica do rio Piquiri localiza-se na região centro-oeste do estado do Paraná, entre as latitudes de $23^{\circ} 00^{\prime} \mathrm{S}$ e $25^{\circ} 30^{\prime} \mathrm{S}$, e ,longitudes $52^{\circ} 00^{\prime} \mathrm{W}$ e $55^{\circ} 30^{\prime} \mathrm{W}$, como pode-se observar na figura 1. 


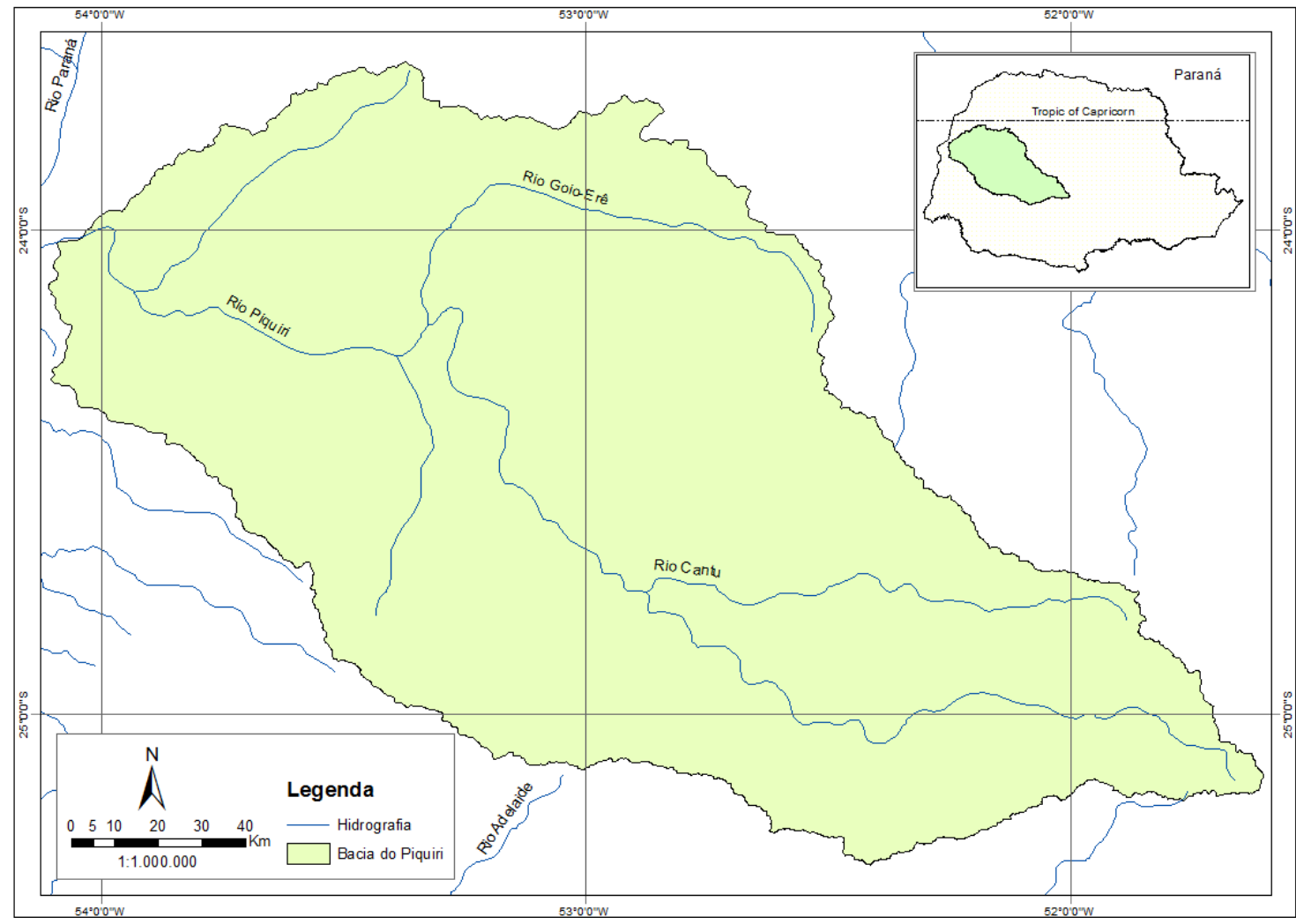

Figura 1: Mapa de localização da bacia hidrográfica do rio Piquiri-PR.

O rio Piquiri percorre aproximadamente $485 \mathrm{~km}$ até sua foz no rio Paraná, na divisa dos municípios de Altônia e Terra Rocha, SEMA (2010). A área de drenagem de toda a bacia é de aproximadamente $24700 \mathrm{~km} 2$ (cerca de 12\% da área total do estado do Paraná) e limita-se ao norte e a leste com a bacia hidrográfica do rio Ivaí, ao sul com a bacia hidrográfica do rio Iguaçu e a oeste o rio Piquiri tem sua foz junto ao rio Paraná.

A bacia hidrográfica do rio Piquiri está localizada numa importante região agrícola do estado do Paraná. A área da bacia abrange 69 municípios do centro-oeste do estado, que em sua maioria são importantes produtores de grãos, produção esta de mais de 2,2 bilhões de reais, de acordo com o Censo Agropecuário do IBGE de 2007.

Para a realização desta pesquisa utilizou-se de dados secundários de precipitação pluviométrica do Instituto das Águas do Paraná, ao qual se escolheu uma quantidade representativa de 41 postos pluviométricos na bacia hidrográfica do rio Piquiri, com série histórica de 35 anos entre 1976 e 2010. 
Os dados de vazão fluvial foram obtidos junto a Agência Nacional de Águas (ANA). Optou-se por utilizar três postos fluviométricos, escolhidos de acordo com a localização geográfica e a série histórica compatível com a precipitação. Escolheu-se o posto Guampará localizado no alto curso do rio principal e com série histórica de 1984 a 2010, o posto Pto. Guarani, no médio curso e o posto Balsa Sta. Maria no baixo curso, ambos com série histórica de 1976 a 2010. Elaborou-se um gráfico comparativo com a precipitação e a vazão média mensal para toda a série histórica analisada.

Determinou-se as áreas de drenagem com a abrangência de cada posto fluviométrico e os respectivos pluviômetros, de acordo com a área de captação, como mostra a figura 2.

A Área 1(A1) que abrange cerca de $1690 \mathrm{~km} 2$ e integra a área de drenagem do posto Guampará e 3 postos pluviométricos, a Área 2 (A2) com $4160 \mathrm{~km} 2$ compreendendo a área de drenagem do posto Pto. Guarani e mais 6 postos pluviométricos e a Área 3 (A3) com 20900 km2 abrangendo a área de drenagem do posto de Balsa Sta. Maria e 36 postos pluviométricos, é a área mais representativa da bacia.

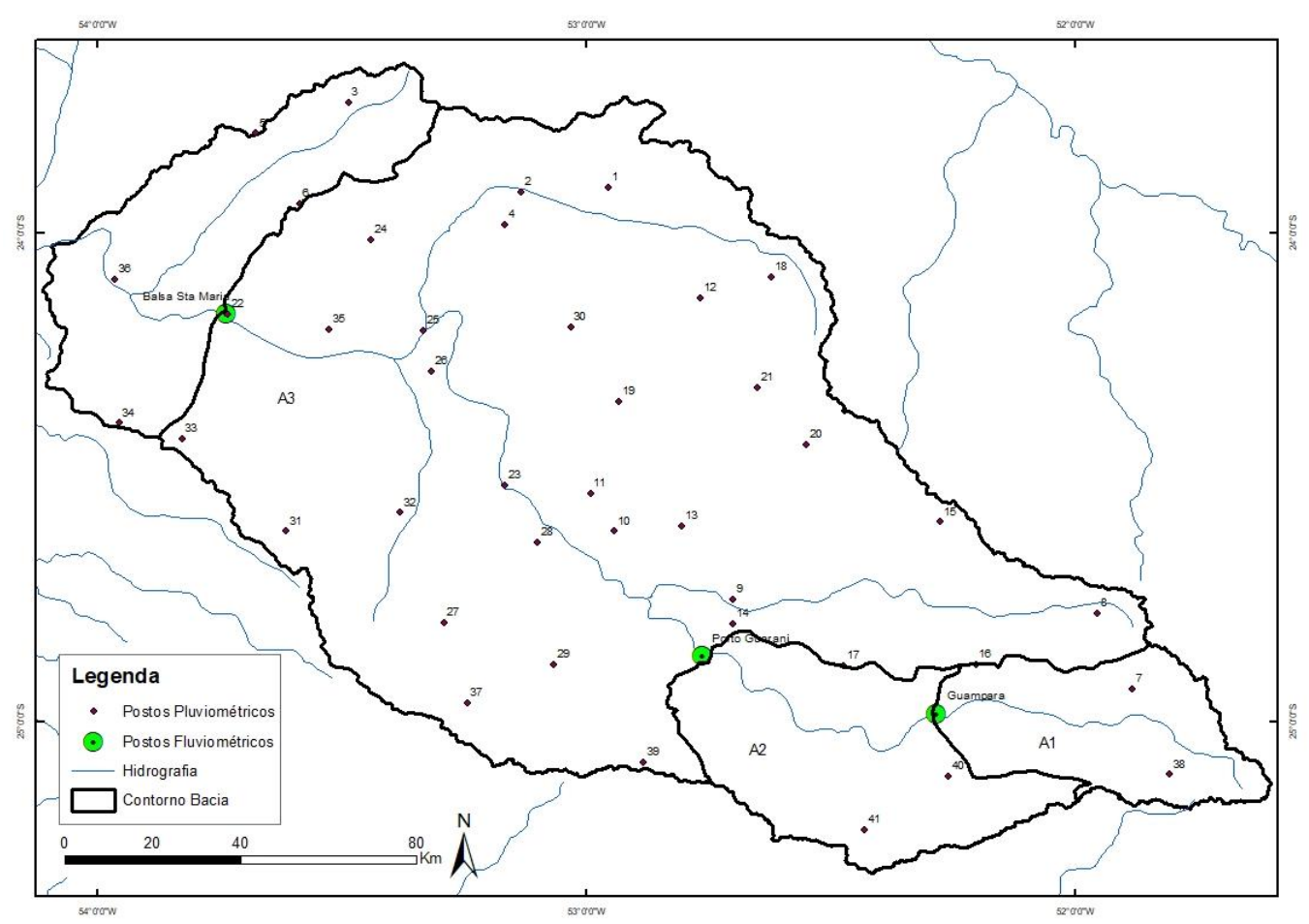

Figura 2: Área de captação determinada pela área de drenagem de cada posto fluviométrico na bacia hidrográfica do rio Piquiri. 
A análise estatística foi realizada com base no uso de boxplots para representar os dados das três áreas de captação (A1, A2 e A3). De acordo com Andrade e Ogliari (2007) esta é uma maneira eficiente de representar medidas de dispersão, além de mostrar as médias e o desvio padrão, o boxplot também apresenta a mediana e os quartis, que indicam a forma, o valor representativo a dispersão e os valores discrepantes da distribuição de dados.

De acordo com Box e Jenkins (1970), Morettin e Toloi (2006), a autocorrelação parcial é útil na identificação da ordem de um modelo autoregressivo, ou seja, são medidas de associação entre valores de séries atuais e anteriores e indicam quais valores de série anteriores são mais úteis para prever valores futuros.

Para determinar a correlação entre a vazão e a precipitação realizou-se a o teste de correlação linear de Pearson (equação 1) entre a precipitação média mensal com a vazão fluvial de cada posto fluviométrico. As correlações foram realizadas com defasagens, com a finalidade de encontrar a existência ou não de atraso entre a ocorrência da precipitação e a transferência da água precipitada para vazão.

$$
\left.\boldsymbol{r}=\frac{\boldsymbol{c}_{X, Y}}{S_{X} S_{Y}} \quad \text { (Equação } 1\right)
$$

$\mathrm{C}_{\mathrm{X}, \mathrm{Y}}$ - Covariância ou variância conjunta das variáveis $\mathrm{X}$ e $\mathrm{Y}$

Sx - Desvio padrão da variável $\mathrm{X}$

SY - Desvio padrão da variável Y

\section{Análise e discussão dos resultados}

O mês de agosto apresenta a menor precipitação média mensal, 81,2 mm, enquanto outubro apresenta a maior, 192,1 mm, uma redução média de 57,8\% na precipitação entre o mês mais chuvoso e o menos chuvoso.

Na figura 3 nota-se que a precipitação média mensal se distribui ao longo do ano com evidente redução no trimestre junho, julho e agosto, nessa época do ano a região sul do país está condicionada à 
presença recorrente dos sistemas frontais, Oliveira (1986) explica que o máximo de avanços de frentes frias no continente ocorre durante o mês de julho.

Os sistemas frontais são responsáveis por trazerem chuvas para a região sul, principalmente sobre o Paraná, isso ocorre porque segundo Grimm (2009) a presença marcante do sistema de alta pressão do Atlântico Sul, o centro de baixa pressão continental enfraquecido e a ausência do fluxo transequatorial para o sul do país na baixa troposfera, cria uma condição de predomínio dos sistemas frontais durante o inverno, ou seja, os outros sistemas atuantes como complexos convectivos de mesoescala (CCMs) e a zona de convergência do atlântico sul (ZCAS), ficam enfraquecidos.

Durante os meses de outubro, novembro, dezembro, janeiro e maio observa-se os maiores valores de precipitação, sento outubro o mês mais chuvoso, nessa época do ano, os sistemas atmosféricos dominantes são, CCMs, linhas de instabilidade e a presença da ZCAS.

De acordo com Grimm (2009), o maior aquecimento da superfície e aporte de umidade para o continente geram uma tendência de estabilizar a atmosfera aumentando a convecção, e a presença dos CCMs, principalmente durante as estações de transição de outubro a abril, e o enfraquecimento dos sistemas frontais frios, que quando presentes, podem se acoplar à ZCAS e aumentar os volumes pluviométricos, geram uma condição de aumento das chuvas nesses meses do ano.

Ainda de acordo com a figura 3, a vazão média mensal da bacia hidrográfica do rio Piquiri é de 508,4 m3/s, a redução das chuvas nos meses de março, abril, junho, julho e agosto resultam consequentemente em diminuição da vazão fluvial, sendo em março a menor vazão média, 383,9 m3/s.

Nos meses de maio e de outubro, novembro, dezembro e janeiro observa-se os maiores valores de vazão, assim como os de precipitação, outubro tem a maior vazão média de $643,1 \mathrm{~m} 3 / \mathrm{s}$. A redução da vazão é de 40,4\% entre outubro e março. 


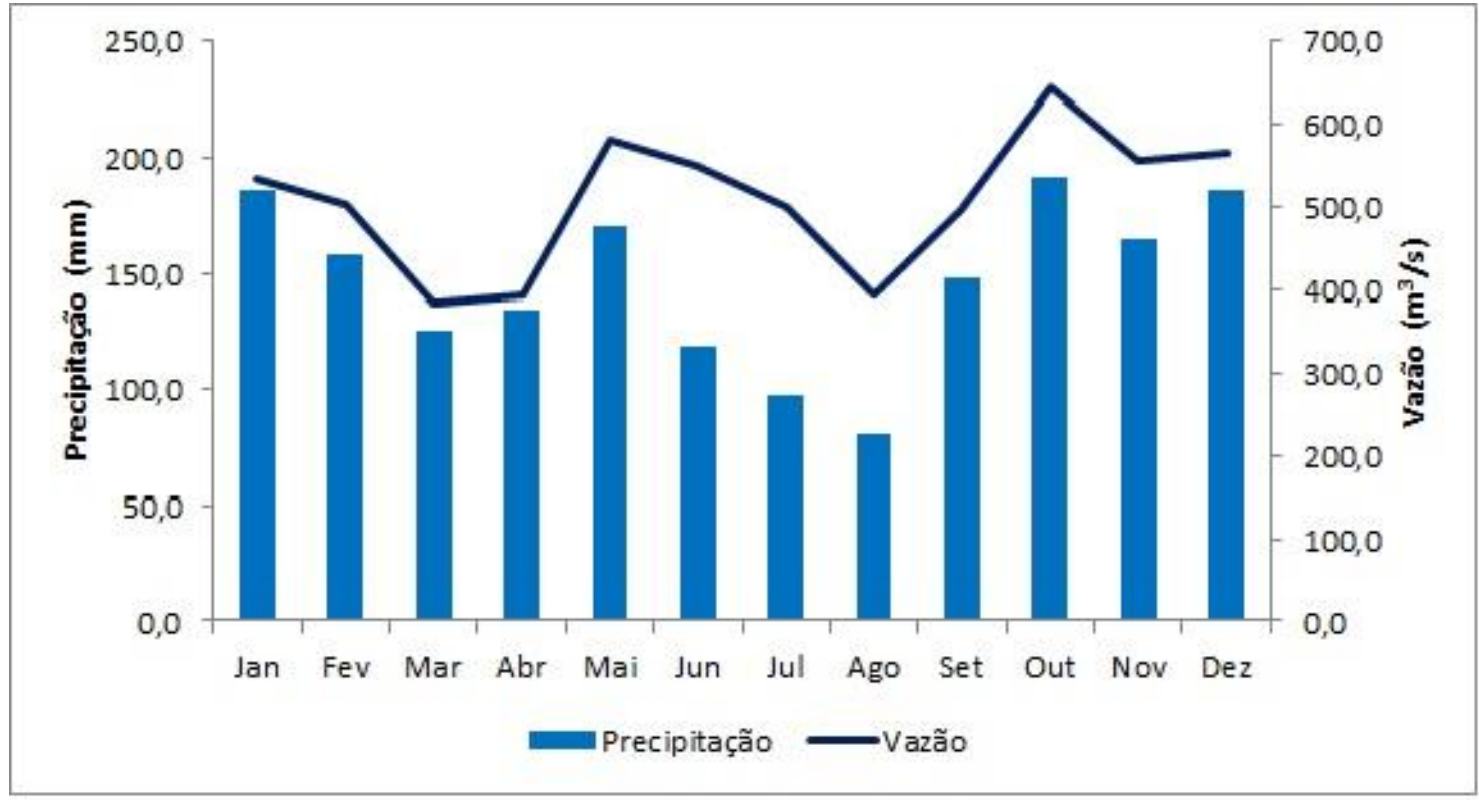

Figura 3: Precipitação e vazão média mensal para o período de 1976-2010 para a bacia hidrográfica do rio Piquiri-PR.

Observando a figura 4 nota-se que a precipitação para as três áreas de drenagem (A1, A2 e A3), apresenta uma considerável variabilidade, com decrescimento na precipitação mediana nos meses de março a agosto, com exceção de maio. Nas três áreas a maior amplitude e variabilidade é observada no mês de maio e setembro, fato já identificado por Correa e Galvani (2017) ao analisar a variabilidade da precipitação para a bacia hidrográfica do rio Piquiri-PR.

Os meses de maio e setembro marcam a transição entre a estação mais quente, o verão, e a mais fria, o inverno. 0 acoplamento de sistemas atmosféricos, principalmente, os sistemas frontais e os processos convectivos se tornam mais efetivos nesses períodos transitórios.

Para as três áreas a menor amplitude ocorre no mês de março, período identificado por Correa e Galvani (2014) como de diminuição das chuvas e temperaturas elevadas, caracterizando março como o mês de menor disponibilidade hídrica para a bacia hidrográfica do rio Piquiri.

Os valores discrepantes (outliers) se repetem nos meses de maio, junho e julho para as três áreas, e aumentam em quantidade conforme se direciona da A1 para A3, indicando quanto mais se direciona para oeste e norte da bacia e a área de cobertura aumenta (A3), a variabilidade da precipitação 
também aumenta, isso porque A3 também integra o setor mais tropicalizado da bacia, conforme demonstrado por Correa (2013).
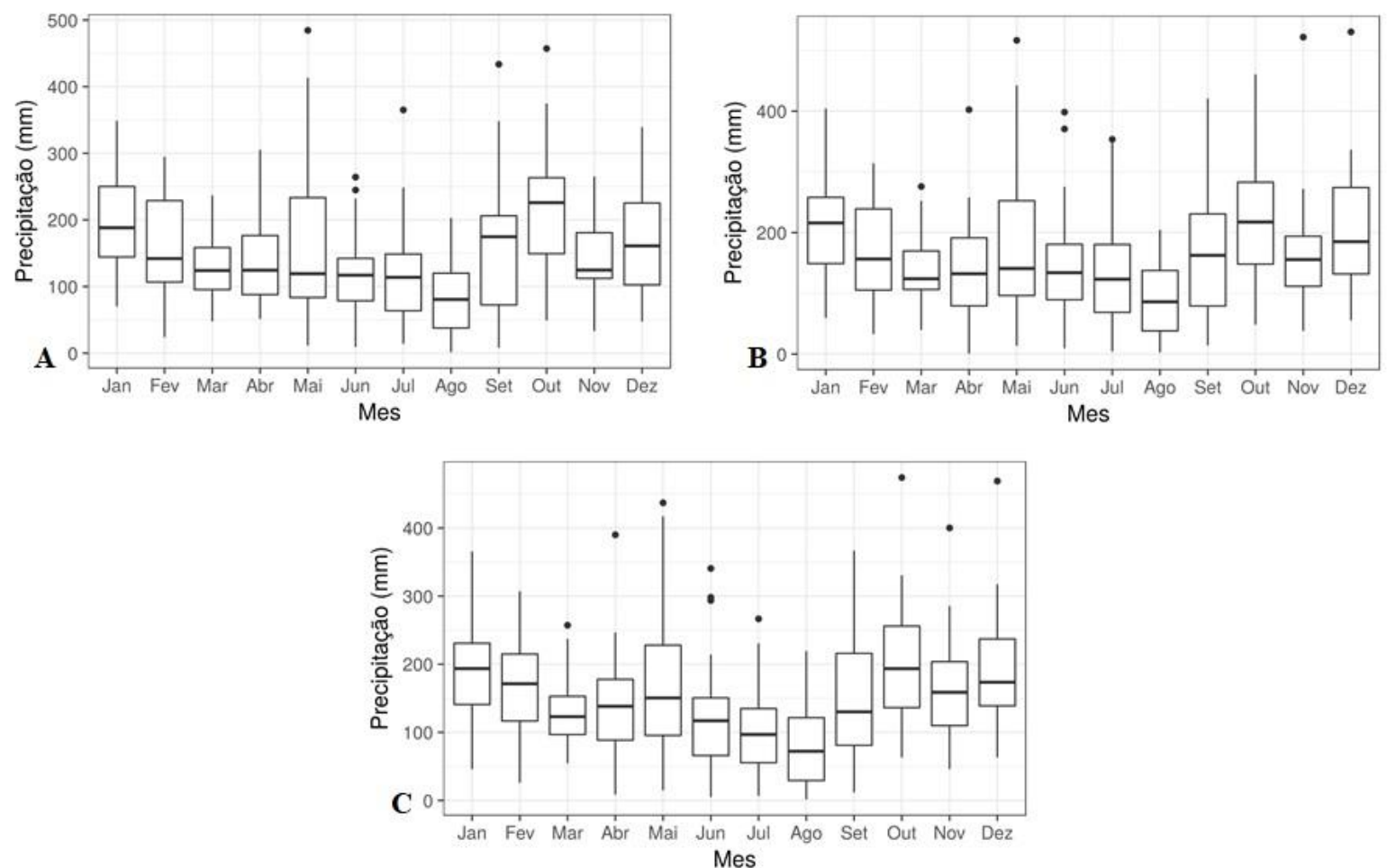

Figura 4: Boxplots da precipitação pluviométrica para as três áreas de drenagem A (Área 1 - Guampará), B (Área 2 - Pto. Guarani) e C (Área 3 - Balsa Sta. Maria) da bacia hidrográfica do rio Piquiri.

No gráfico da função de autocorrelação, figura 5, observa-se que apesar da correlação da precipitação em um determinado mês com a dos meses anteriores no período de um ano ser significativa para algumas defasagens (1 mês, 7 meses, 11 meses e 12 meses), o valor encontrado é muito baixo (menor que $10 \%$ ), indicando a defasagem zero meses a mais confiável. 

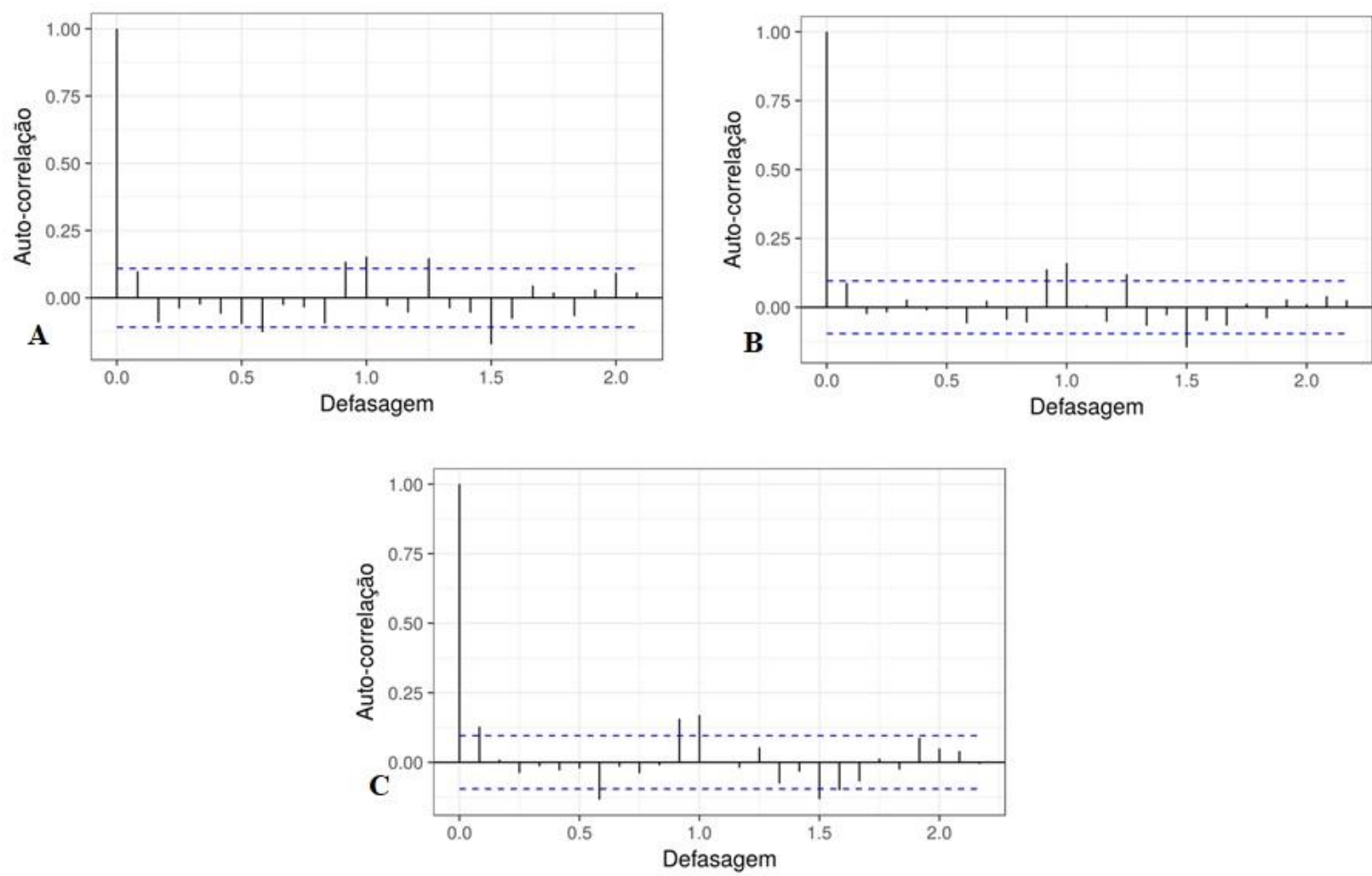

Figura 5: Autocorrelação com defasagens entre precipitação do mês de referência e o mês anterior, A (Área 1 - Guampará), B (Área 2 - Pto. Guarani) e C (Área 3 - Balsa Sta. Maria) na bacia hidrográfica do rio Piquiri-PR.

Para a vazão fluvial, figura 6 , a variabilidade é maior que a observada na precipitação (figura 4). Nas três áreas a maior amplitude e variabilidade é observada no mês de maio e outubro, e a menor amplitude e variabilidade no mês de março.

O número de outliers variam entre 15-16 para as três áreas, sendo os extremos observados nos meses de abril, maio e outubro (especialmente na A3).

O aumento do número de outliers na vazão (média de 15 para as três áreas de drenagem), se comparado com a precipitação pluviométrica (média de 8 para as três áreas de drenagem) é de aproximadamente o dobro, indicando a complexidade da variabilidade que envolve a dinâmica da vazão fluvial. 

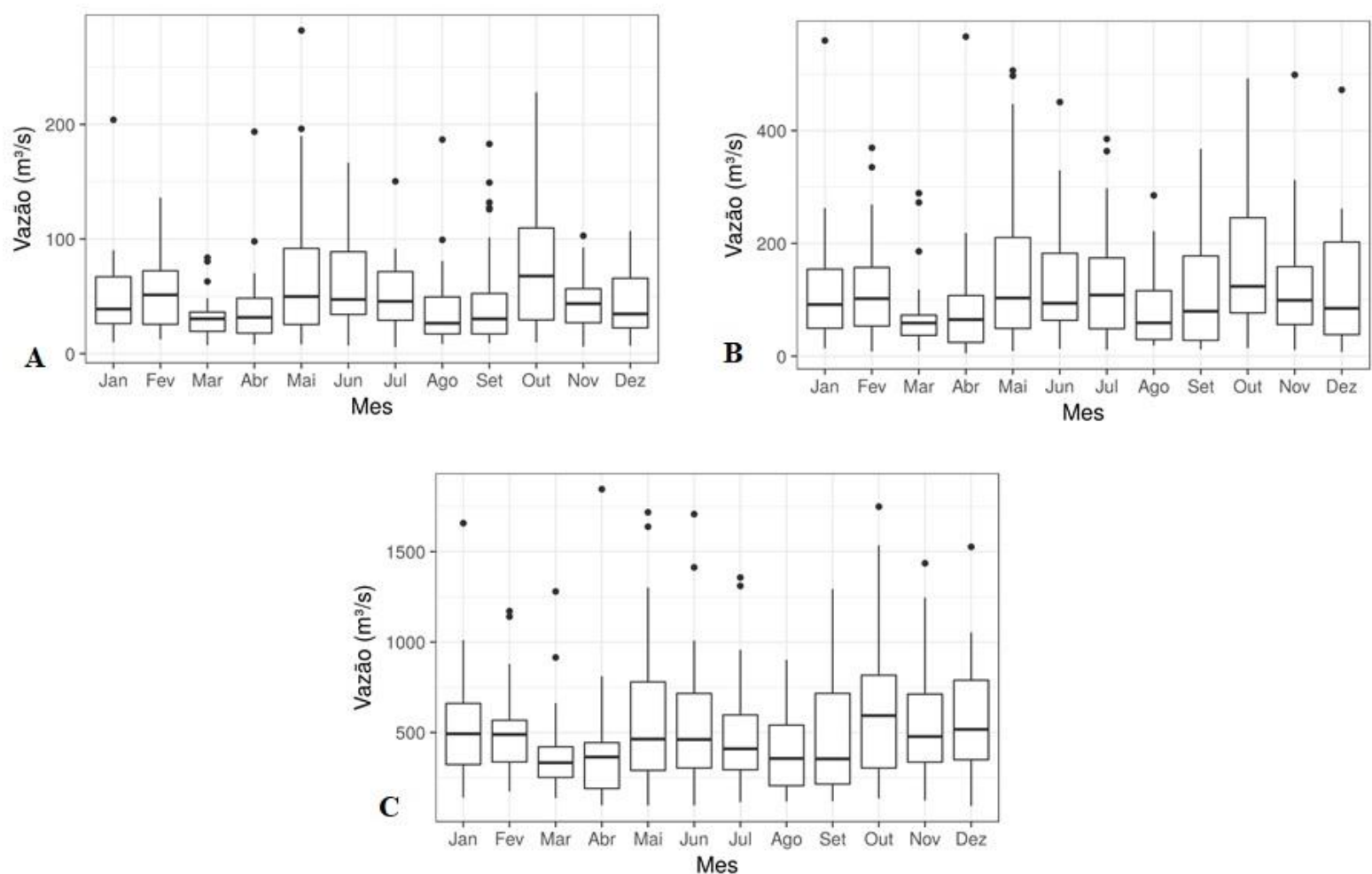

Figura 6: Boxplots da vazão fluvial para as três áreas de drenagem A (Área 1 - Guampará), B (Área 2 - Pto. Guarani) e C (Área 3 - Balsa Sta. Maria) da bacia hidrográfica do rio Piquiri.

A função de autocorrelação, figura 7, mostra que a correlação da vazão em um determinado mês com a dos meses anteriores no período de um ano foi significativa para algumas defasagens, principalmente para A2 e A3, sendo que a defasagem de 1 mês para A3 apresentou 50\%, porém a mais confiável continua sendo a defasagem de zero meses.

Diferente da precipitação pluviométrica, a função de autocorrelação da vazão mostrou maior dependência com o mês seguinte 

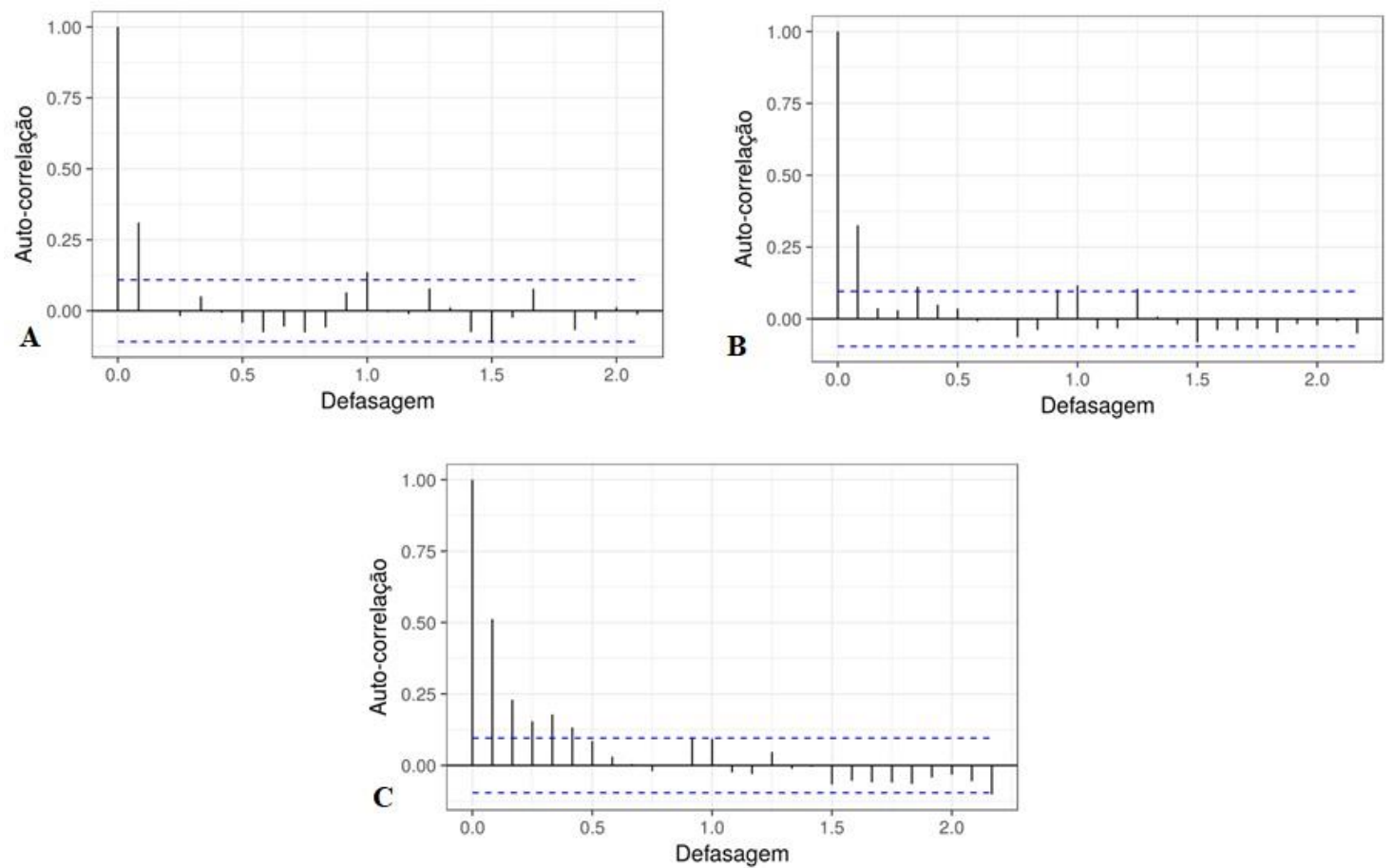

Figura 7: Autocorrelação com defasagens entre vazão do mês de referência e o mês anterior, A (Área 1 - Guampará), B (Área 2 - Pto. Guarani) e C (Área 3 - Balsa Sta. Maria) na bacia hidrográfica do rio Piquiri-PR.

Ao observar a figura 8 com as correlações com defasagem entre a precipitação e a vazão para A1, A2 e A3, nota-se que as correlações com zero defasagem foram 0,75; 0,80 e 0,70 respectivamente. Porém as correlações com um mês de defasagem também foram significativas. Sendo confiável considerar a defasagem entre a precipitação e a vazão fluvial de até um mês para a bacia hidrográfica do rio Piquiri.

Observa-se que há associação expressiva, medida por uma correlação 0,7 entre a vazão e a precipitação sem defasagem para A3, ou seja, um aumento da precipitação implica em um aumento simultâneo na média da vazão. Existe uma associação menor da vazão com a precipitação defasada em um mês, mas a correlação 0,50 encontrada pode ser não conclusiva. A defasagem entre a precipitação e a vazão deve ser menor que 1 mês, na ordem temporal de semanas ou dias, o que não é detectável na escala mensal utilizada nesta pesquisa.. 

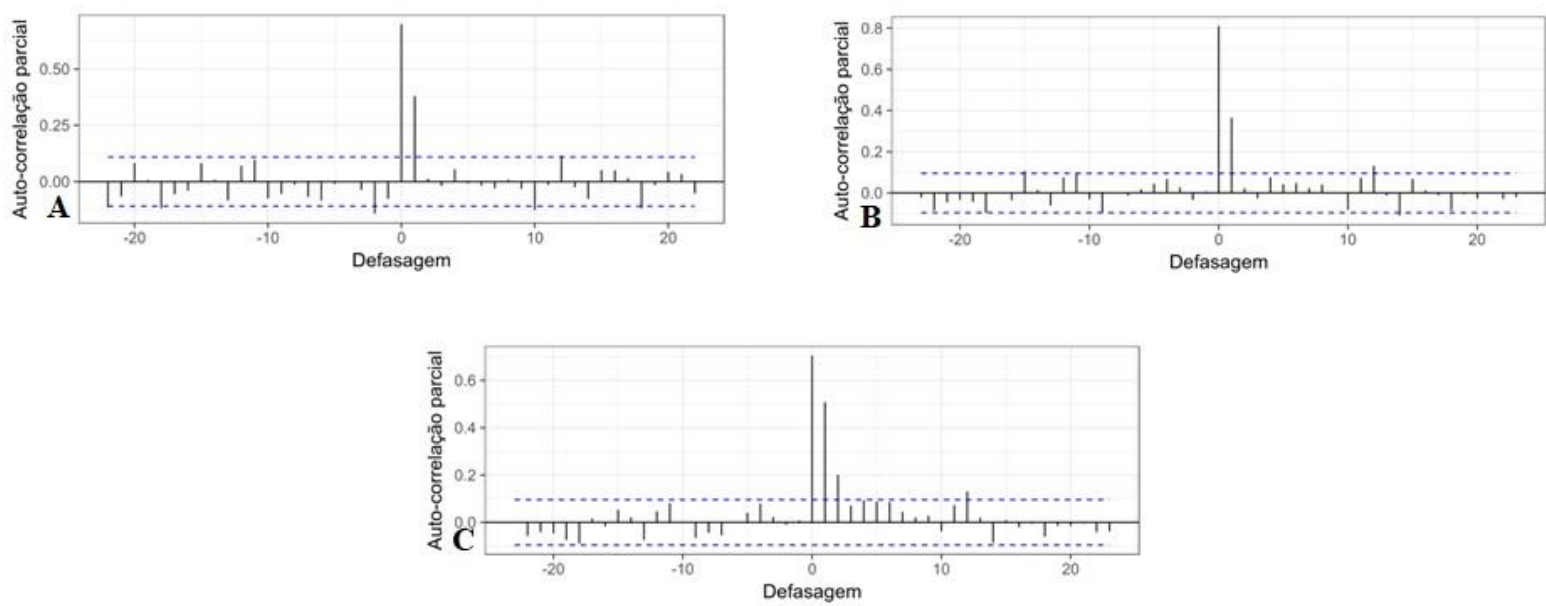

Figura 8: Autocorrelação com defasagens entre precipitação e vazão, A (Área 1 - Guampará), B (Área 2 - Pto. Guarani) e C (Área 3 - Balsa Sta. Maria) na bacia hidrográfica do rio Piquiri-PR.

A figura 9, mostra os gráficos de dispersão da vazão e da precipitação mensal para cada área de drenagem, devido a prováveis pontos influentes, é notável à medida que a precipitação aumenta a vazão também aumenta, pois a água presente na bacia não é utilizada para fins externos, como geração de energia elétrica, de tal forma que este fator não precisa ser considerado.
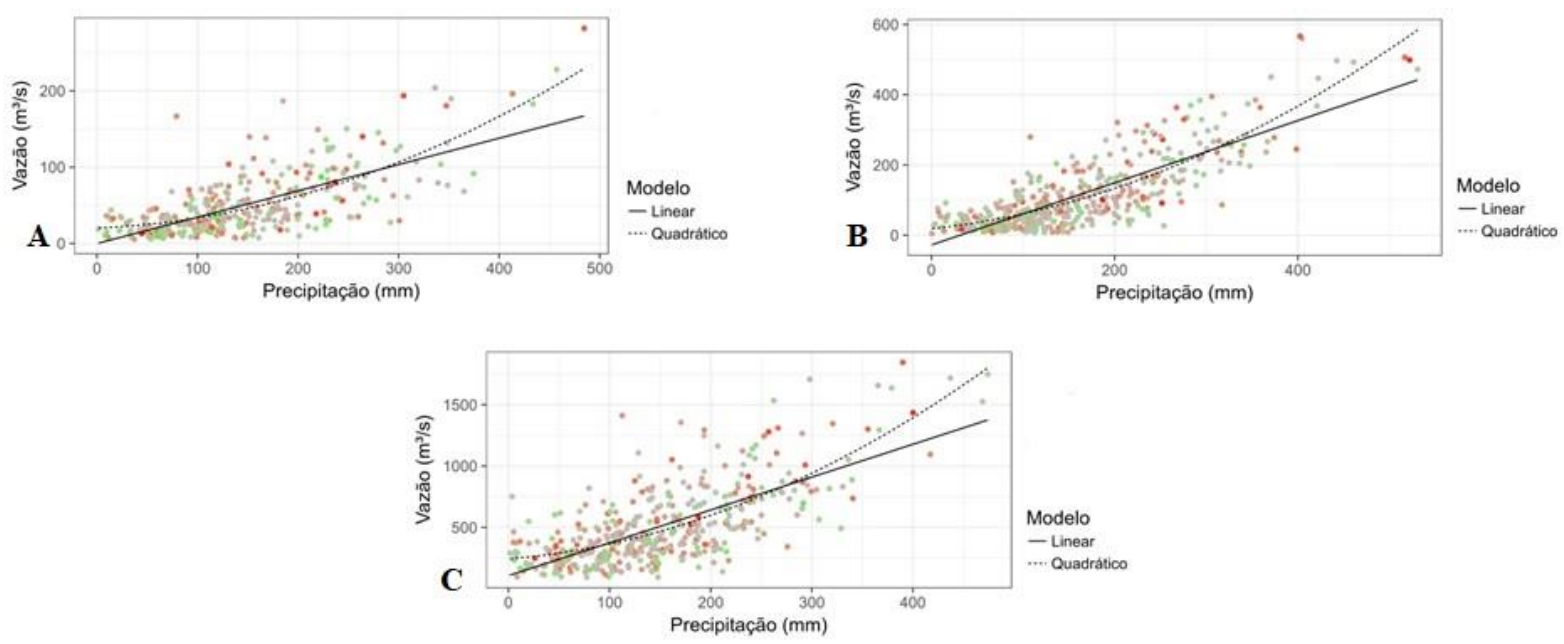

Figura 9: Gráficos de correlação entre precipitação e vazão, A (Área 1 - Guampará), B (Área 2 - Pto. Guarani) e C (Área 3 - Balsa Sta. Maria) na bacia hidrográfica do rio Piquiri-PR.

\section{CONSIDERAÇÕES FINAIS}


O mês de agosto apresenta a menor precipitação média mensal, $81,2 \mathrm{~mm}$, enquanto outubro apresenta a maior, 192,1 mm, a vazão média mensal da bacia hidrográfica do rio Piquiri é de 508,4 m3/s.

Os gráficos boxplots mostraram que maio apresenta a maior variabilidade da precipitação e outubro é o mês com maior variabilidade para a vazão, enquanto o mês de março apresentou a menor variabilidade da precipitação e da vazão. Os outliers mais expressivos na precipitação foram observados nos meses de maio, na vazão foram nos meses de abril, maio e outubro.

As funções de autocorrelação indicam que para a precipitação e a vazão sem defasagem tem-se maior confiabilidade, indicando que a defasagem entre precipitação e vazão fluvial na bacia hidrográfica do rio Piquiri deve ser inferior a 1 mês, na escala de semanas ou dias.

A água representada pela precipitação e vazão funcionam como elemento dinamizador dos fenômenos físicos. A interação destes fenômenos é complexa e abre uma infinidade de possibilidades de estudos futuros.

\section{Bibliografía}

ANDRADE, D. F.; OGLIARI, P. J. Estatística para ciências agrárias e biológicas com noções de experimentações. Florianópolis: Ed. Da UFSC, 2007, 432 p.

AZEVEDO, L.C. Análise da Precipitação Pluvial da Bacia do Rio Iguaçu - Paraná. 2006. 123f. Dissertação (Mestrado). Programa de Pós-Graduação em Geografia. Universidade Estadual de Maringá, Maringá, 2006.

BALDO, M.C. Variabilidade Pluviométrica e a Dinâmica Atmosférica da Bacia do Rio Ivaí. 2006. 153 f. Tese (Doutorado). Programa de Pós-Graduação em Geografia. Universidade Estadual Paulista "Júlio de Mesquita Filho", Presidente Prudente, 2006.

BERTONI, J. C.; TUCCI, C. E. M. Precipitação. In: TUCCI, C. E. M. Hidrologia: Ciência e aplicação. Porto Alegre: Ed. da Universidade - UFRGS, ABRH, 2001.

BOX, G.E.P.; JENKINS, G.M. Time Series Analysis: Forecasting and Control. San Francisco: Holden-Day, 1970. 
CORREA, M. G. G. Distribuição espacial e variabilidade da precipitação pluviométrica na bacia do rio Piquiri-PR. 2013. Dissertação (Mestrado em Geografia) - Faculdade de Filosofia, Letras e Ciências Humanas, Universidade de São Paulo, São Paulo, 2013.

CORREA, M. G. G.; GALVANI, E. Variabilidade espacial e temporal do balanço hídrico climatológico para a bacia hidrográfica do rio Piquiri-PR. In: XI Simpósio Brasileiro de Climatologia Geográfica, Curitiba. Variabilidades e mudanças climáticas globais: Estado da arte e perspectivas para a interação sociedade natureza, 2014.

CORREA, M. G. G.; GALVANI, E. Análise estatística da variabilidade da precipitação pluviométrica para a bacia hidrográfica do rio Piquiri-PR. Boletim Paulista de Geografia. São Paulo, n. 96, p. 1-10, 2017.

GRIMM, A. M. Variabilidade interanual do clima no Brasil. In: CAVALCANTI, I. F. de A. et al. Tempo e clima no Brasil. São Paulo: Oficina de Textos, 2009.

HEWLETT, J.D.; HIBBERT, A.R. Factors affecting the response of small watersheds to precipitation in humid areas. In: SOPPER, W.E.; LULL, H.W. Forest hydrology. New York: Pergamon Press. 1967.

KÖPPEN, W. Climatologia: com un estúdio de los climas de la tierra. México. Ed. Fondo de Cultura Econômica, 1948.

MORETTIN, P. A.; TOLOI, C. M. C. Análise de Séries Temporais. 2. ed. São Paulo: Edgard Blucher, 2006.

OLIVEIRA, A. S. Interações entre sistemas frontais na América do Sul e a convecção da Amazônia. 1986. Dissertação (Mestrado em Meteorologia) - Instituto Nacional de Pesquisas Espaciais, São José dos Campos, 1986.

SECRETARIA DE ESTADO DO MEIO AMBIENTE E RECURSOS HÍDRICOS. Bacias hidrográficas do Paraná: Série histórica. Governo do Estado do Paraná, 2010.

SHELTON, M. L. Hydroclimatology: Perspectives and applications. Cambridge: Cambridge University Press, 2009.

TERASSI, P.M.B. Variabilidade pluviométrica e a erosividade na unidade hidrográfica Pirapó, Paranapanema III e IV, Paraná. Dissertação (Mestrado). Maringá, Universidade Estadual de Maringá, 2015.

TUCCI, C. E. M. Escoamento Superficial. In: TUCCI, C. E. M. Hidrologia: Ciência e aplicação. Porto Alegre: Ed. da Universidade - UFRGS, ABRH, 2001.

Yoshimoto, T.; SUETSUGI, T. Comprehensive flood disaster prevention measures in Japan. Hydrological Processes and Water Management in Urban Areas: IAHS Publ. n. 198, 1990.

ZANDONADI, L. As chuvas da bacia do rio Paraná, Brasil: Um estudo do ritmo climático e algumas considerações sobre a vazão hídrica. 2013. 206f. Tese (Doutorado). Programa de Pós-Graduação em Geografia, Universidade Estadual Paulista "Júlio de Mesquita Filho", Rio Claro, 2013. 